\title{
Current Role of Decompressive Craniectomy In the Management of Raised ICT; A Report with Clinical and Technical Illustrations
}

\author{
Raghunath Avanali.M.Ch ${ }^{1}$, Vidya G.MD ${ }^{2}$, Sundeep.V.K.MS ${ }^{1}$, Bhagavatula Indira Devi.M.Ch ${ }^{3}$ \\ ${ }^{1}$ Department of Neurosurgery, Government Medical College, Alappuzha,Kerala, India. PIN 688005 \\ ${ }^{2}$ Physical medicine and Rehabilitation, Thaluq Hospital, Njarakkal, Kerala, India \\ ${ }^{3}$ Department of Neurosurgery, NIMHANS, Bangalore, India
}

*Corresponding author: RaghunathA, Assistant Professor, Neurosurgery, GovtTD.Medical college, Alappuzha, Kerala state, Pin- 688005, India

Submission: April 03, 2018; Published: July 05, 2018

\begin{abstract}
Persistent acute high intracranial pressure culminates in death or severe disability. When pharmacological measures fail to control it, decompressive craniectomy is offered. Superiority of decompressive craniectomy over best medical management for improved outcome is disputed. In thisarticle we have highlighted the indications, techniques, and current role of decompressive craniectomywith clinical illustrations.
\end{abstract}

\section{Introduction}

Management of intractably raised intracranial pressure (ICP), which complicates many neurosurgical and neurological diseases, is challenging even with the development of new pharmacological and supportive measures. Persistently raised ICP hampers cerebral perfusion and causes cerebral herniations and both will lead to brainstem compromise resulting in high incidence of mortality or serious morbidity in these patients. Concept of removal of part of the skull to provide space for the swollen brain has been recognized for more than a century. Decompressive craniectomy was first introduced in 1901 by Kocher to alleviate intracranial hypertension and further elaborated by Cushing [1-3]. Earlier, decompressive craniectomy was used as a salvage procedure when all other attempts failed. Presently, many centres use it as an adjuvant to other measures to reduce ICP to prevent secondary brain injury (early and very early decompressive craniectomy). Studies which looked for the effectiveness of decompressive craniectomy especially for early decompression, have produced controversial results. But it is still continues to be an undoubtedly important surgical procedure for a neurosurgeon because of its obvious benefit in many conditions like cerebro venous thrombosis, hemispheric infarction, traumatic brain injury with focal mass lesions or diffuse severe edema.

\section{Technical aspects}

Surgery is performed usually, as either unilateral fronto tempero parietal craniectomy or bifrontal craniectomy. Less extensive forms can be performed like fronto temporal or temporoparietal craniectomy for more localised lesions. A paramedian or median suboccipital craniectomy is done for infratentorial pathology. Circular decompression and sub temporal decompression is not practised routinely. A large fronto temporoparietal craniectomy provide as much as $92.6 \mathrm{~cm}^{3}$ additional space [4]. Jan Mracek et al. [5] described osteoplastic decompressive craniotomy as an alternative to decompressive craniectomy in a limited group of 23 patients with various conditions and was proposed to avoid a second surgery for cranioplasty [5]. Similarly, another method called 'tucci flap' is described in which bone flap is attached to only one side of cranium by plates which acts like a hinge [4]. In certain situations bilateral fronto-temporoparietal or unilateral hemicraniectomy plus Bifrontal craniectomy may be required. Depending on the surgeon's experience, variations in flap and craniotomy can be performed. The craniectomy design should also consider the primary source of mass effect. If there is no focal pathology as in the case of diffuse traumatic brain injury, a bifrontal craniectomy may be considered.

\section{Incision and craniectomy}

For a fronto temporo parietal decompressive craniectomy we usually perform a question mark like incision starting anterior to tragus, going upwards and behind the ear lobule to a maximum of 2 finger breadth posteriorly and turning superiorly to touch the parietal eminence and further anteriorly to behind the hairline, and 
staying away from midline. As the incision comes anteriorly it moves closer to midline and just behind hairline at midline it crosses to the opposite side for about $1 \mathrm{inch}$. Care should be taken to preserve the anterior branch of superficial temporal artery. Base of such a flap will be facing towards basitemporal and basifrontal regions. Flap can be raised along with or separately from temporalis muscle. A frontotemperoparietal decompressive craniectomy is performed. Temporal base is nibbled flush to the floor of middle cranial fossa which is in level with the upper border of root of zygoma. On frontal side frontal air sinus should be avoided if possible or to be exteriorised properly to avoid postoperative CSF rhinorrhoea and infection [6]. At the parasagittal region care should be taken to stay 1.5 to $2 \mathrm{~cm}$ ipsilateral to midline, to avoid injury to sinus or its draining veins. Another modification of the incision is one that starts above the mastoid, behind the ear and further continued as previously described. Since the vascular supply from temporal artery is preserved in this flap one may go more posteriorly. When this flap is made care should be taken to place burr hole above the asterion. When the lesion is more posterior, (posterior temporal and parieto occipital) an inverted horse shoe shaped flap can be taken. It starts in front of tragus, goes superiorly behind hairline if possible, till about one inch from midline and curves posteriorly to end about 1 to $2 \mathrm{~cm}$ above inion -mastoid line (surface marking for transverse sinus) staying about $2 \mathrm{~cm}$ ipsilateral to midline. A Bifrontal craniectomy requires a bicoronal flap and craniectomy extends from the floor of anterior cranial fossa to coronal suture superiorly and pterion laterally.

\section{Clinical Illustrations}

\section{Case report 1(Figure 1)}
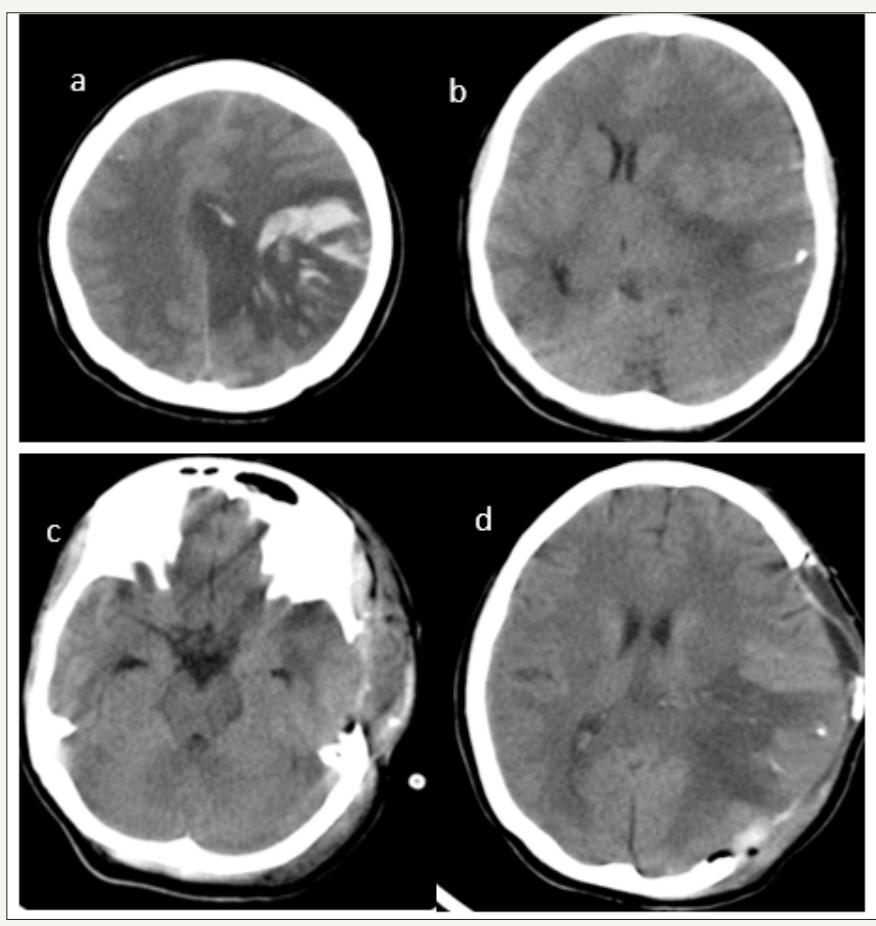

Figure 1: Case no 1(a)And (b) show pre operative images and (c) and (d) post operative images. Note the almost normalization of midline shift and opening ofbasal cistern in post operative images. 
20 years old female who had delivered a healthy baby 3 days back presented in emergency department with one episode generalised tonic clonic seizure followed by altered sensorium of 4 hours duration. On examination patients' GCS was E1M2V1 with pupillary asymmetry. Right pupil was $2 \mathrm{~mm}$ sluggishly reacting to light and left pupil was $5 \mathrm{~mm}$ not reacting to light. External ocular movements were sluggish. CT head showed a left parietal cortical vein thrombosis with mass effect and midline shift of $1.2 \mathrm{~cm}$. In view of the age, pathology (CVT) and with a short period of altered sensorium it was decided to offer decompressive craniectomy and she underwent large temporo parietal decompressive craniectomy. Dura was opened in the centre in a cruciate manner and augmentative duroplasty done with pericranial graft. Bone flap was placed in abdominal subcutaneous pocket. In postoperative period patient made substantial recovery. Before discharge she was obeying simple commands, was able to indicate needs. She had right sided hemiplegia. At 3 months follow up patient was conscious, oriented and had right hemiparesis but could ambulate with support. Her functional outcome on extended Glasgow outcome scale was 4 (upper severe disability)

\section{Case report 2 (Figure 2)}

4 years old girl presented with altered sensorium of one day duration. There was no history suggestive of any head injury or other preexisting illness. On examination GCS was E1M3V1 with right pupil larger than left and external ocular movements were sluggish. CT Head showed right sided acute subdural hematoma. Patient underwent right side frontotemporo parietal craniectomy and evacuation of subdural heamtoma. But after clearing the clots in the parasagittal area by saline irrigation there was severe brain bulge. Augmentative duroplasty done. Bone flap could not be replaced in the calvarium. Postsurgery patient's GCS was E1M1V1 with bilateral pupils not reacting. Post op CT showed right ICA and PCA territory infarct and appearance of inter hemispheric haematoma. Patient expired on $4^{\text {th }}$ post-operative day. In our experience appearance of inter hemispheric bleed was not uncommon whenever an attempt was made to clear the clots from the parasagittal brain surface in cases of acute subdural heamtoma. We strongly recommend that clots near the midline should not be removed as it is not contributing to midine shift or mass effect.

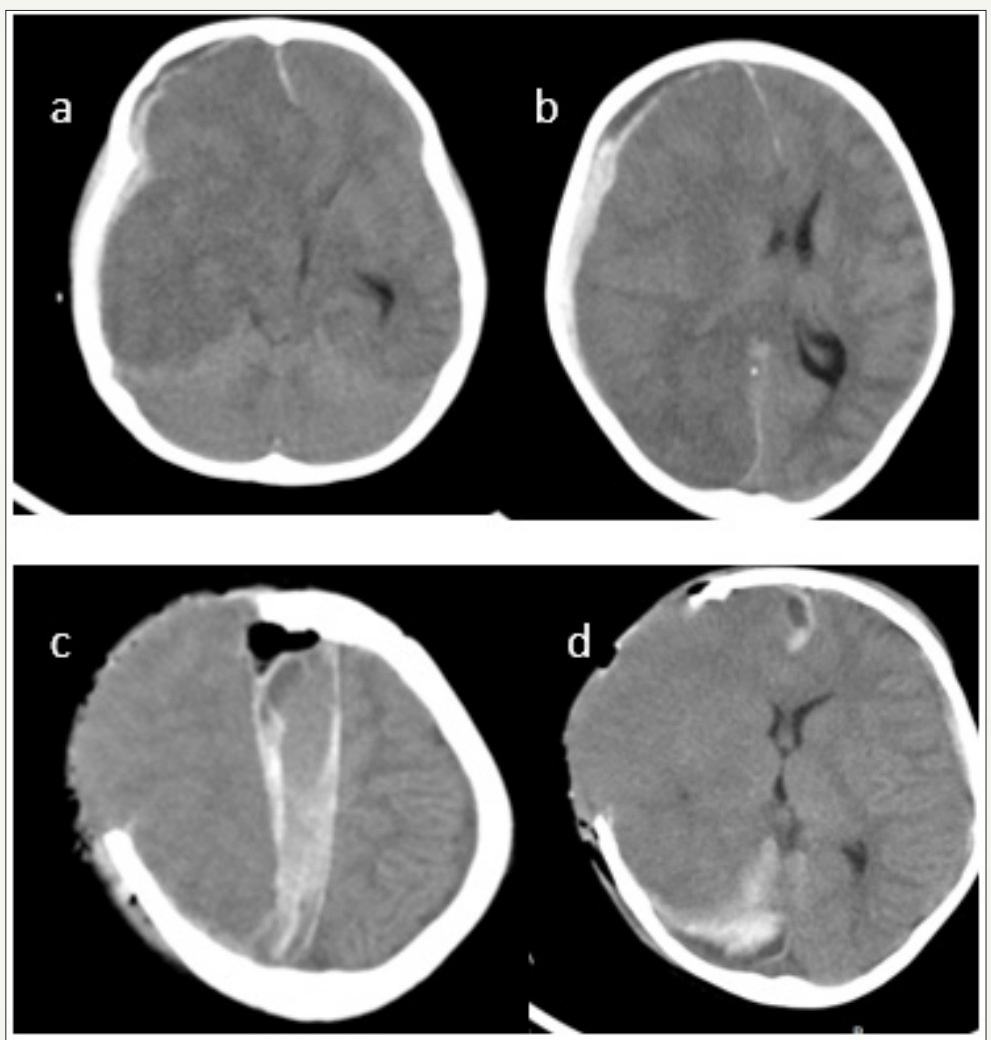

Figure 2: Case no.2 (a) and (b) shows right sided thickmixed density subdural hematoma

(c) and (d) are postoperative images. (c)show right ICA infarct, appearance of inter hemispheric subdural hematoma(d) shows normalization of midline shift. Overallthe size of craniectomy is slightly small. Also note the external cerebral Herniation.

\section{Case report 3 (Figure 3)}

A 40 years old lady admitted in emergency department 5 hours after road traffic accident. GCS was E4M6V4 with pupils bilaterally equal and reacting. Patient was evaluated by CT head which showed bilateral basifrontal contusions. Patient was started on cerebral antioedema measures and next day could be discharged to a local hospital. After 3 days patient was referred because of neurological deterioration. On examination GCS was E1M5V1 with right pupil larger than left pupil. Repeat CT head showed increase in the perilesional oedema around the contusions with obliteration of basal cisterns. Like the first CT head repeat imaging also did not show any midline shift or increased mass effect on neural structures. 
Hence decision making for a decompressive craniectomy to treat malignant cerebral oedema was difficult. But clinical picture was suggestive of transtentorial herniation. Also, she did not showed any improvement with a short trial of antioedema measures. Please note that in malignant cerebral oedema most centres offers decompressive craniectomy when the ICP is persistently above $20 \mathrm{~mm}$ of $\mathrm{Hg}$ for a period of 30 minutes despite adequate sedation, muscle paralysis, pharmacological antioedema measures and ventricular CSF drainage. Here patient was already showing signs of herniation we have not preferred to document ICP which will consume additional time. Bifrontal decompressive craniectomy and augmentative duroplasty was done. Patient improved within one day. At discharge patient was conscious, obeying though slightly confused without any focal neurological deficits. At 3 months follow up functional outcome on extended Glasgow outcome scale was 7(lower good recovery). Patient successfully underwent bone cranioplasty.
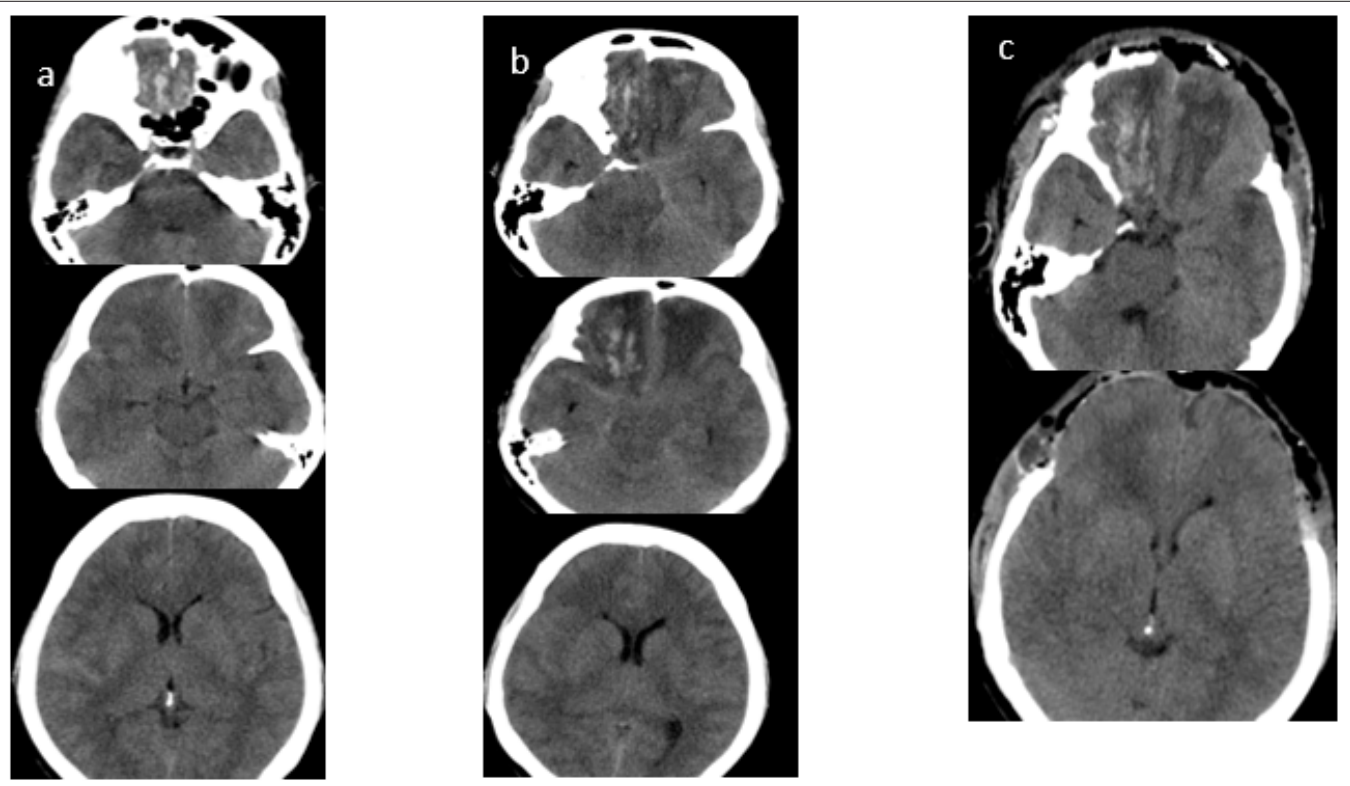

Figure 3: Caseno. 3. (a)show the first 5-hour CT head,(b) repeat CT head at 3RD day. Note that basal cisterns are obliterated.In (C) which is post-operative CT head basal cisterns are opened up. Radiological changes correlated well with clinical improvement.

\section{Case report4 (Figure 4)}

35 years old gentleman presented with one day history of left sided weakness followed by altered sensorium. On examination GCS was E3M5V3 with pupillary asymmetry and left side hemiplegia. CT head showed Right ICA territory infarct with mass effect and midline shift of 9mm. Right frontotemporo parietal hemicraniectomy and augmentative duroplasty was done. Patient improved well. At discharge patient was conscious, obeying, verbalising well. Left side motor weakness improved, and he could lift upper limb and lower limb against gravity. Follow up is awaited.

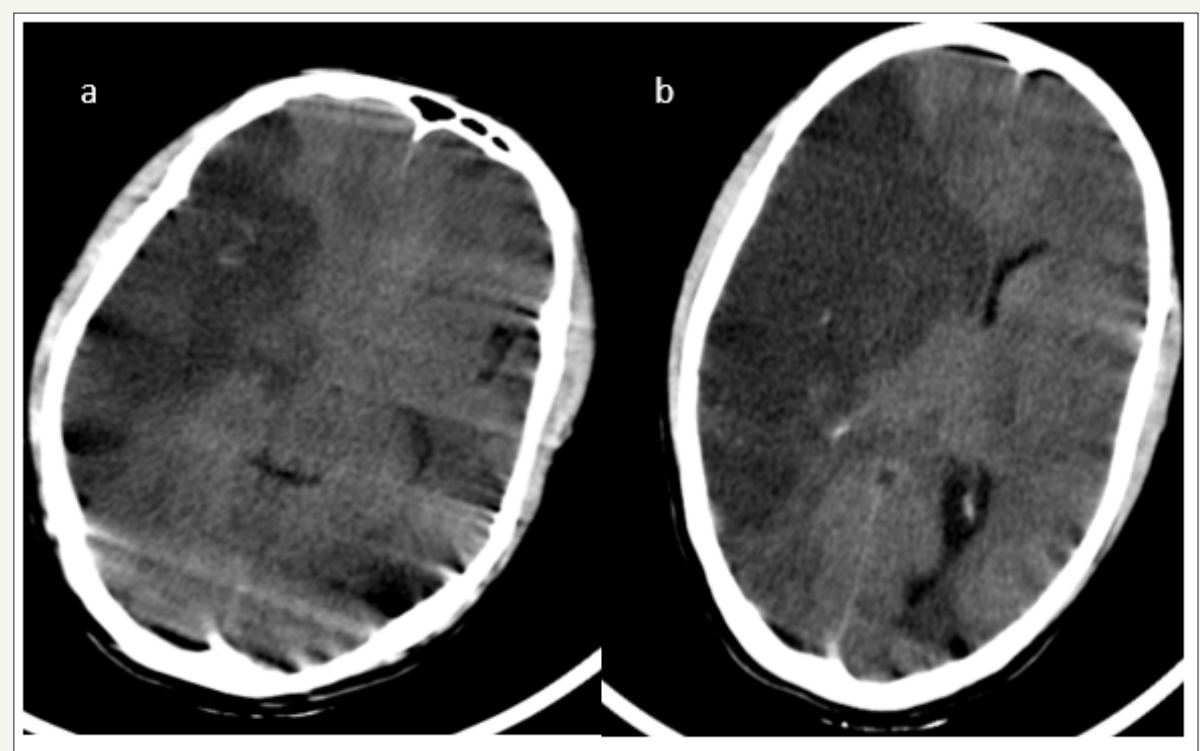

Figure 4: Case no4. (a) and (b)show right ICA territory infarct. Note that basal cisterns are obliterated. Midline shift of 9mmis present. Images also show significant motion artifacts as the patient was agitated and restless. 


\section{Case report 5 (Figure 5)}

50 years old male patient presented with left hemi paresis of 3 days duration and altered sensorium of 2 days. Patient was a chronic alcoholic. On examination patients' GCS was E1M3V1 with right pupil larger than left and left side hemiplegia. CT picture could have been easily mistaken for an ICA territory infarct with areas of hemorrhagic transformation. But uneven margins and presence of empty delta sign on contrast sequence suggested the diagnose of venous infarct. Patient underwent right side hemicraniectomy. Patient improved well. At 6 months follow up patient was conscious, obeying, but there was only minimal improvement of motor weakness. His functional outcome at 6 months on extended Glasgow outcome scale was 3 (Lower severe disability).
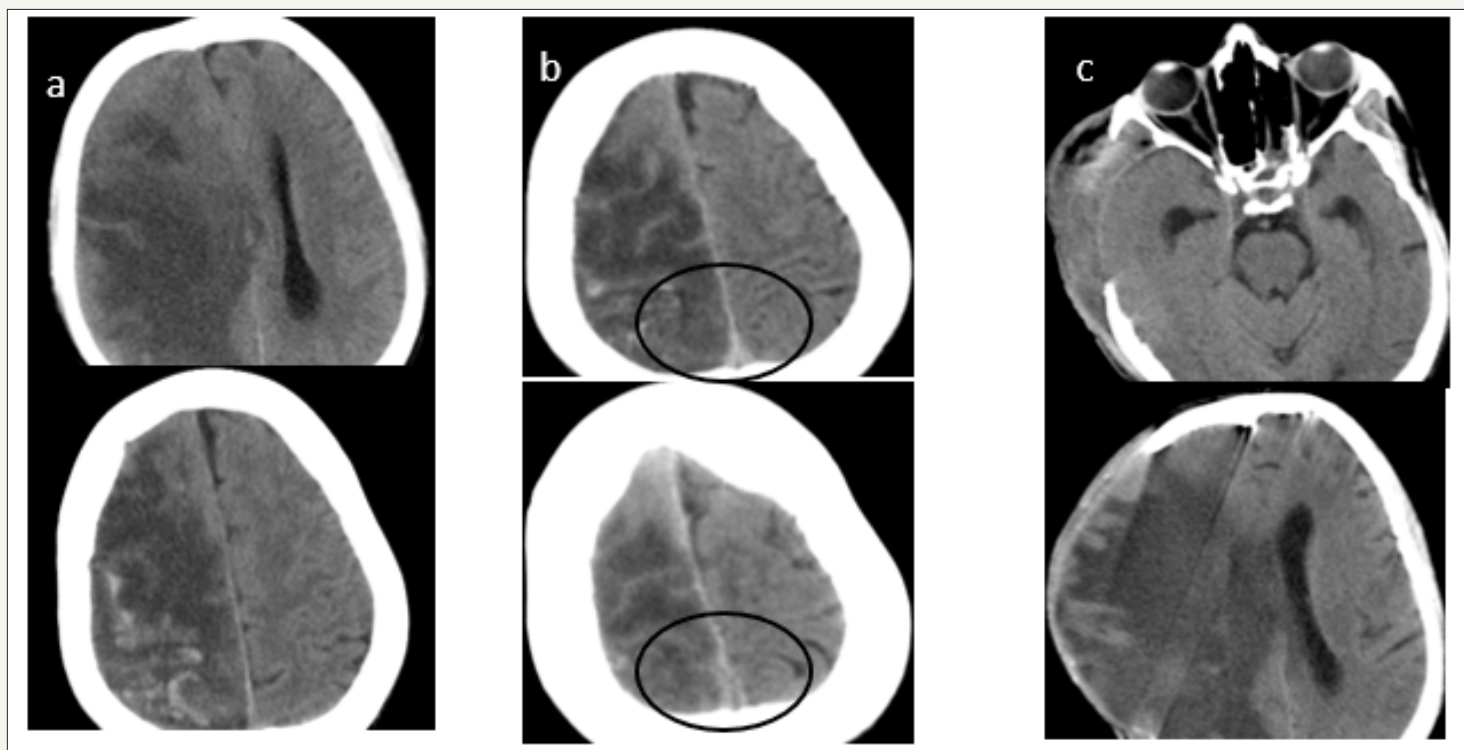

Figure 5: Case no.5 (a)plain images, (b)with contrast.note the empty delta sign in superior sagittal sinus.(circled), (c) postoperative images. note thesignificant external cerebral herniation.

\section{Discussion}

Elevated ICP is defined as intracranial pressure above 15 to $20 \mathrm{~mm}$ of $\mathrm{Hg}$ when measured in any intracranial compartment namely extradural, subdural, parenchymal, intraventricular [11]. Interventions are aimed at reducing intracranial pressure (ICP), maximizing cerebral perfusion, and minimizing cerebral metabolic demands. General manoeuvres to reduce the ICP include head elevation, normothermia, volume resuscitation, sedation. If these general manoeuvres fail, first line therapeutic measures are started. These are cerebrospinal fluid (CSF) drainage, moderate hypocapnia (pCO2 of 30 to $35 \mathrm{~mm} \mathrm{Hg}$ ), and mannitol administration [12,13].

Severe intracranial hypertension does not respond to medical management in 10 to $15 \%$ of head injury patients [14]. When these first-level measures fail to control ICP, Suggested second-tier measures include high-dose barbiturates, intense hyperventilation (pCO2< $30 \mathrm{~mm} \mathrm{Hg}$ ), increasing mean arterial blood pressure, mild or moderate hypothermia, and decompressive craniectomy. Of these, only the use of barbiturates has reached a Level II recommendation (based on Class II evidence) $[12,15]$. Despite the recommendations of the BTF guidelines on the use of barbiturates, a Cochrane systematic review did not find evidence that the use of barbiturates improves the outcome in severe traumatic brain injury and alternatives to barbiturates and in particular decompressive craniectomy is recommended in the treatment of refractory high ICP [11].

\section{Rationale of the DECOMPRESSIVE CRANIECTOMY and Outcome}

In Cooper et al. [16] study $(n=73) 6$ months outcome for diffuse traumatic brain injury who underwent decompressive craniectomy reported good recovery at 6 months for $4 \%$, moderate disability for $26 \%$, severe disability for $39 \% .12 \%$ of the patients continued to be in vegetative state. Mortality at 6 months was $19 \%$. However, the role of decompressive craniectomy in TBI is not inarguably established and the Cochrane review conclude that presently no results are available to confirm or refute the effectiveness of decompressive craniectomy in traumatic brain injury [11]. DECRA trial concluded that in adults with severe diffuse traumatic brain injury and refractory intracranial hypertension, early bifrontotemporoparietal decompressive craniectomy though decreased intracranial pressure and the length of stay in the ICU but was eventually associated with a worse outcome at 6 months [16]. But it is also known that patients can still continue to improve after 6 months and delayed neurological recovery up to 18 months after decompressive craniectomy is not uncommon [17-19]. Substantial recovery beyond 18 months is seldom observed. And the results of DECRA cannot be generalised as the subjects recruited had diffuse brain injury without a large hematoma $[18,20]$. Studies of pediatric diffuse traumatic injury found decompressive craniectomy useful and suggested that it should be performed as early as possible if the ICP raises above $20 \mathrm{~mm}$ of $\mathrm{Hg}[21,22]$. There are also inherent limitations for applying an outcome predilection model (like in 
CRASH) for assessing usefulness of decompressive craniectomy $[19,23]$. So, in nutshell, treating neurosurgeons' experience and instincts along with patient caretakers' aspirations and wishes should influence decision making rather the information available from well-designed studies alone.

Stroke is the other common indication for decompressive craniectomy. In hemispheric infarct, difference in morbidity associated with dominant versus nondominant hemispheric affection, influence selection of treatment in many centres. Mortality of malignant middle cerebral artery infarction range from $40 \%$ to $80 \%[24,25]$. No medical treatment has been proven effective. Even though role of decompressive craniectomy for saving life is clear, its impact on quality of life is controversial especially in dominant cerebral hemispherical infarct. Patients who derive the most benefit are younger (especially < 50 years of age), undergo craniectomy earlier ( $<48$ hours after stroke), when the GCS score more than 8 with worsening neurologic status during hospital stay and cerebral edema [26-28]. Vahedi et al. [25] has done the pooled analysis from three European randomised controlled trials; the French Decompressive Craniectomy in Malignant Middle Cerebral Artery Infarct trial, the German Decompressive Surgery for the treatment of malignant infarction of the Middle Cerebral Artery trial, and the Dutch Hemicraniectomy after Middle Cerebral Artery Infarction with Life-threatening Edema trial (DECIMAL, DESTINY, HAMLET). More patients in the decompressive-surgery group than in the control group had a modified Rankin score(mRS) less than 4 (75\% vs. $24 \%$; pooled absolute risk reduction $51 \%$ ), a modified Rankin score less than $3(43 \%$ vs $21 \%$ ), and survived (78\% vs $29 \%$ ), and numbers needed to treat was two for survival with $\mathrm{mRS} \leq 4$, four for survival with $\mathrm{mRS} \leq 3$, and two for survival irrespective of functional outcome. So, every 10 hemicraniectomies performed, five patients will escape death, at 6 months one of these patients will have mild disability, one will have moderate disability, and three will have moderate-to-severe disability. Overall decompressive surgery undertaken within 48 hours of stroke onset reduces mortality and increases the number of patients with a favourable longterm functional outcome even in patients with affection of dominant side [29]. Mortality reduction is by prevention of herniation while morbidity reduction may be partly by improvement of pneumbra and improvement of overall brain perfusion [9].

Results of decompressive craniectomy for cerebrovenous thrombosis seems to be better than other conditions. All parenchymal lesions in CVT are not true infarcts, but rather are areas of mixed vasogenic and cytotoxic edema with or without hemorrhagic transformation [30]. Even in patients with bilateral fixed pupils, recovery is expected in one third of them. Severe dependency was observed only in $6 \%$ compared to $35 \%$ in patients with malignant middle cerebral artery infarct [30]. Haemorrhage dominated lesions and deep cerebral venous involvement influenced the outcome adversely [31].

\section{Complications of decompressive craniectomy}

As in any other neurosurgical interventions complications like intracranial hematoma, CSF leak, or infections are not uncommon.
Complications which are specific to this particular procedure are due to patho physiologic changes in ICP, CSF circulation, and cerebral blood flow following removal of a part of calvarium. SP Ban et al. [14] in a study of 89 patients with traumatic brain injury noted incidence of various complications as; formation of a hematoma remote to craniectomy region in $5.6 \%$, postoperative epilepsy in $3.4 \%$, External cerebral herniation (defined as herniation more than $1.5 \mathrm{~cm}$ in the centre of defect) in $14.6 \%$, post traumatic hydrocephalus in $11.2 \%$, syndrome of trephined in $9.0 \%$, Mortality at 6 months in 23.6\%. External brain herniation can lead to cortical lacerations, contusions, tearing of surface vessels [32]. These adverse effects not only affect the quality of life but also influence second surgical interventions like VP shunt and cranioplasty [33].

The syndrome of the trephined is characterised by symptoms of headache, seizures, dizziness, tinnitus, unsteadiness, tremors, mood swings, behavioural disturbances, spells of altered sensorium and increase in pre-existing post traumatic paresis [3]. After decompressive craniectomy, the scalp above the bone defect sinks because of a lack of bone support, which transmits atmospheric pressure directly to the brain, reduces the subarachnoid space, and exerts pressure on the underlying cortex, which perturbs CSF circulation and cerebral blood flow. This syndrome should be considered as a cause for secondary neurological deterioration in patients with decompressive craniectomy. Symptoms often responds well to cranioplasty within 24 hours [34].

Patients with decompressive craniectomy who are on external ventriculostomies, ventriculoperitoneal shunts, or a lumbar CSF drains may develop paradoxical herniation. The effect of atmospheric pressure along with gravity on the intracranial contents leads to a herniation syndrome. Treatment include Trendelenberg position, hydration, stopping hyper osmolar agents like mannitol, and clamping CSF drainage. Effects similar to paradoxical Herniation can be produced by CSF collection in subgaleal space which accumulated under pressure because of ball valve effect. This is called as external brain tamponade [32].

\section{Summary}

Decompressive craniectomy continues to be an important tool in the armamentarium of a neurosurgeon as a life saving measure despite its well-known complications. Only its impact on overall quality of life in certain conditions is questionable. To deny the right to live is also equally questionable. So, decision should be influenced not only from the information available from the present day literature but should also account treating neurosurgeon's experience and patient's family member's wishes.

\section{Acknowledgement}

The study has not received any financial aid and authors alone are responsible for the content and writing of the article.

\section{References}

1. Bao YH, Liang YM, Gao GY, Pan YH, Luo QZ, et al. (2010) Bilateral decompressive craniectomy for patients with malignant diffuse brain swelling after severe traumatic brain injury: a 37-case study. J Neurotrauma 27(2): 341-347. 
2. Gouello G, Hamel O, Asehnoune K, Bord E, Robert R, et al. (2014) Study of the long-term results of decompressive craniectomy after severe traumatic brain injury based on a series of 60 consecutive cases. The Scientific World Journal 2014: 207585.

3. Mokri B (2010) Orthostatic headaches in the syndrome of the trephined: resolution following cranioplasty. Headache 50(7): 1206-1211.

4. Huang X, Wen L (2010) Technical considerations in decompressive craniectomy in the treatment of traumatic brain injury. Int J Med Sci $7(6): 385-390$.

5. Mracek J, Choc M, Mork J, Vacek P, Mracek Z (2011) Osteoplastic decompressive craniotomy-an alternative to decompressive craniectomy. Acta Neurochir (Wien) 153(11): 2259-2263.

6. Zanaty M, Chalouhi N, Starke RM, Clark SW, Bovenzi CD, et al. (2015) Complications following cranioplasty: incidence and predictors in 348 cases. J Neurosurg 123(1): 182-188.

7. Csokay A, Nagy L, Novoth B (2001) Avoidance of vascular compression in decompressive surgery for brain edema caused by trauma and tumor ablation. Neurosurg Rev 24(4): 209-213.

8. Yao Y, Mao Y, Zhou L (2007) Decompressive craniectomy for massive cerebral infarction with enlarged cruciate duraplasty. Acta Neurochir (Wien) 149(12): 1219-1221.

9. Slotty PJ, Kamp MA, Beez T, Beenen H, Steiger HJ, et al. (2015) The influence of decompressive craniectomy for major stroke on early cerebral perfusion. J Neurosurg 123(1): 59-64.

10. Schwarz F, Dunisch P, Walter J, Sakr Y, Kalff R, Ewald C (2016) Cranioplasty after decompressive craniectomy: is there a rationale for an initial artificial bone-substitute implant? A single-center experience after 631 procedures. J Neurosurg 124(3): 710-715.

11. Sahuquillo J, Arikan F (2006) Decompressive craniectomy for the treatment of refractory high intracranial pressure in traumatic brain injury. Cochrane Database Syst Rev 25(1): CD003983.

12. Brain trauma foundation guidelines 2007.

13. Grindlinger GA, Skavdahl DH, Ecker RD, Sanborn MR (2016) Decompressive craniectomy for severe traumatic brain injury: clinical study, literature review and meta-analysis. SpringerPlus 5(1): 1605.

14. Ban SP, Son YJ, Yang HJ, Chung YS, Lee SH, et al. (2010) Analysis of complications following decompressive craniectomy for traumatic brain injury. J Korean Neurosurg Soc 48(3): 244-250.

15. Ho KM, Honeybul S, Yip CB, Silbert BI (2014) Prognostic significance of blood-brain barrier disruption in patients with severe nonpenetrating traumatic brain injury requiring decompressive craniectomy. I Neurosurg 121(3): 674-679.

16. Cooper DJ, Rosenfeld JV, Murray L, Arabi YM, Davies AR, et al. (2011) Decompressive craniectomy in diffuse traumatic brain injury. N Engl J Med 364(16): 1493-1502.

17. Ho KM, Honeybul S, Litton E (2011) Delayed neurological recovery after decompressive craniectomy for severe nonpenetrating traumatic brain injury. Crit Care Med 39(11): 2495-2500.

18. Honeybul S, Janzen C, Kruger K, Ho KM (2013) Decompressive craniectomy for severe traumatic brain injury: is life worth living? Neurosurg 119: 1566-1575.
19. Honeybul S, Ho KM, Lind CR, Gillett GR (2014) Validation of the CRASH model in the prediction of 18-month mortality and unfavorable outcome in severe traumatic brain injury requiring decompressive craniectomy. J Neurosurg 120(5): 1131-1137.

20. Vashu R, Sohail A (2011) Decompressive craniectomy is indispensible in the management of severe traumatic brain injury. Acta Neurochir (Wien) 153: 2065-2066.

21. Csokay A, Emelifeonwu JA, Fugedi L, Valalik I, Lang J (2012) The importance of very early decompressive craniectomy as a prevention to avoid the sudden increase of intracranial pressure in children with severe traumatic brain swelling (retrospective case series). Childs Nerv Syst 28(3): 441-444.

22. Adelson PD (2015) Editorial: Severe traumatic brain injury and decompressive craniectomy. J Neurosurg Pediatr p. 1-3.

23. Honeybul S, Ho KM, Lind CR, Gillett GR (2010) Decompressive craniectomy for neurotrauma: the limitations of applying an outcome prediction model. Acta Neurochir (Wien) 152(6): 959-964.

24. Harscher S, Reichart R, Terborg C, Hagemann G, Kalff R, et al. (2006) Outcome after decompressive craniectomy in patients with severe ischemic stroke. Acta Neurochir (Wien) 148(1): 31-37.

25. Vahedi K, Hofmeijer J, Juettler E, Vicaut E, George B, et al. (2007) Early decompressive surgery in malignant infarction of the middle cerebral artery: a pooled analysis of three randomised controlled trials. Lancet Neurol 6(3): 215-222.

26. Fraser JF, Hartl R (2005) Decompressive craniectomy as a therapeutic option in the treatment of hemispheric stroke. Curr Atheroscler Rep 7: 296-304.

27. Kilincer C, Asil T, Utku U, Hamamcioglu MK, Turgut N, et al. (2005) Factors affecting the outcome of decompressive craniectomy for large hemispheric infarctions: a prospective cohort study. Acta Neurochir (Wien) 147: 587-594.

28. Woertgen C, Erban P, Rothoerl RD, Bein T, Horn M, Brawanski A (2004) Quality of life after decompressive craniectomy in patients suffering from supratentorial brain ischemia. Acta Neurochir (Wien) 146(7): 691695.

29. Daou B, Kent AP, Montano M, Chalouhi N, Starke RM, et al. (2016) Decompressive hemicraniectomy: predictors of functional outcome in patients with ischemic stroke. J Neurosurg 124(6): 1773-1779.

30. Ferro JM, Crassard I, Coutinho JM, Canhao P, Barinagarrementeria F, et al. (2011) Decompressive surgery in cerebrovenous thrombosis: a multicenter registry and a systematic review of individual patient data. Stroke 42(10): 2825-2831.

31. Zhang S, Zhao H, Li H, You C, Hui X (2016) Decompressive craniectomy in hemorrhagic cerebral venous thrombosis: clinicoradiological features and risk factors. J Neurosurg p. 1-7.

32. Akins PT, Guppy KH (2008) Sinking skin flaps, paradoxical herniation, and external brain tamponade: a review of decompressive craniectomy management. Neurocrit Care 9(2): 269-276.

33. Heo J, Park SQ Cho SJ, Chang JC, Park HK (2014) Evaluation of simultaneous cranioplasty and ventriculoperitoneal shunt procedures. J Neurosurg 121(2): 313-318.

34. Honeybul S, Ho KM (2011) Long-term complications of decompressive craniectomy for head injury. J Neurotrauma 28(6): 929-935. 
Creative Commons Attribution 4.0 International License

For possible submissions Click Here

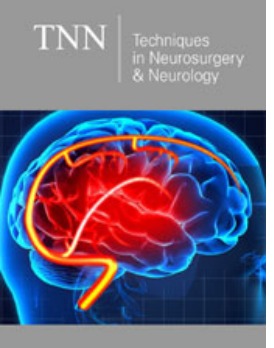

Techniques in Neurosurgery \& Neurology

\section{Benefits of Publishing with us}

- High-level peer review and editorial services

- Freely accessible online immediately upon publication

- Authors retain the copyright to their work

- Licensing it under a Creative Commons license

- Visibility through different online platforms 